\title{
Pork-Barrel Spending under Cournot Legislators and the Quantity Equation
}

\author{
Gerasimos T. Soldatos ${ }^{1}$ \\ ${ }^{1}$ Department of Business Administration, American University of Athens, 15232 Athens, Greece \\ Correspondence: Gerasimos T. Soldatos, Department of Business Administration, American University of Athens, \\ 43 Pindarou str., 56224, Thessaloniki, Greece. Tel: 30-693-809-9056. E-mail: soldgera@yahoo.com
}

Received: December 30, 2014

Accepted: January 9, 2015

Online Published: February 25, 2015

doi:10.5539/ijef.v7n3p153

URL: http://dx.doi.org/10.5539/ijef.v7n3p153

\begin{abstract}
This note makes the following two points based on Cournot utility functions of the legislators and on the government budget constraint viewed from the perspective of the equation of exchange. Without logrolling, i.e. with different perceptions of the budget constraint, there can be such a legislature preference structure that can turn a pork-barrel project into welfare-enhancing public expenditure depending on economic circumstances. With logrolling, i.e. with agreement at least regarding the size of the budget, the "pork" may be taken out of the project regardless the economic conjuncture. These results are independent of the utility function used, while the use of the quantity equation serves only as the simplest macroeconomic framework in which the two general points herein may be made.
\end{abstract}

Keywords: pork-barrel spending, budget deficit, quantity equation, cournot legislators, logrolling

The budget should be balanced, the Treasury should be refilled, public debt should be reduced, and the arrogance of officialdom should be tempered and controlled lest Rome become bankrupt. Marcus Tullius Cicero (106-43BC).

\section{Introduction}

Pork-barrel spending can arise even under a homogeneous electorate as a result of redistributive promises to gain political advantage and is a source of budget deficits, (Lizzeri, 1999). The focus here is these deficits and to the extent pork-barrel spending demands are accommodated somehow, any aspirations for a balanced budget are doomed to fail, indeed, (see also Chari \& Cole, 1995; Battaglini \& Coate, 2008). And, neither legislature size nor bicameralism is expected to reverse the subsequent debt accumulation and tax increase (see e.g. Ricciuti, 2004). Unless, of course, pork-barrel spending happens to be conducive to growth (see e.g. Lanciay \& Russoz, 2013). In a Cournot type interaction between the advocator of such spending and a balanced budget proponent, a leader-follower rather than Nash equilibrium can be the case with or without logrolling. And, even if the leader is the thrifty delegate, some pork-barrel spending will always be authorized for reasons if not anything else of consensus politics. In principle, the spending conceded to by a balanced budget proponent will be less than the spending desired by a pork-barrel pleader. But, in practice, economic circumstances may end up facilitating the realization of the spending targeted by the latter. The next section shows that this depends on the interplay between legislator preferences and the macroeconomic conjuncture as described elementarily by quantity-of-theory-of-money considerations. This is the case when legislators hold different views of the government budget and refuse to compromise them by logrolling. A consensus about the budget constraint reached through the trading of votes to ensure maximum real output growth, takes the "pork" out of pork-barrel spending regardless the economic conjuncture. The third section concludes this discussion by pointing to the redistributive aspect of such spending.

\section{The Analysis}

Let the supporter of pork-barrel spending and the thrifty delegate be designated by subscripts 1 and 2 , respectively. Let $P G$ be the public expenditure at the price level $P$, with $P G_{1}=\mu P G_{2}, \mu>1$, so that:

$$
U_{1}=a_{1}+b_{1} P G_{1}-c_{1} P G_{2}=a_{1}+\left[b_{1}-\left(c_{1} / \mu\right)\right] P G_{1}
$$

and 


$$
U_{2}=a_{2}+b_{2} P G_{2}-c_{2} P G_{1}=a_{2}+\left(b_{2}-c_{2} \mu\right) P G_{2}
$$

where $U$ denotes utility while the $a$ 's, $b$ 's, and $c$ 's are some positive constants. Actor $i, i=1,2$, derives utility from $P G_{i}$ but disutility from $P G_{j}, j=1,2, j \neq i$. The budget constraints contemplated are:

$$
P G_{I}=P T+\Delta M+\Delta B
$$

and

$$
P G_{2}=P T+\Delta M
$$

implying thereby that:

$$
\mu=1+\frac{\Delta B}{P T+\Delta M}
$$

where $B$ is government borrowing and $\Delta$ is the one-period-change operator. For simplicity, the interest payments, $r B$, serving the debt are ignored, where $r$ is the nominal interest. The first-order conditions from the corresponding Lagrangeans yield that:

$$
\mu_{1}=\frac{c_{1}}{b_{1}-\lambda_{1}}
$$

and

$$
\mu_{2}=\frac{b_{2}-\lambda_{2}}{c_{2}}
$$

where $\lambda_{i}$ are the Lagrangean multipliers, and $\mu_{i}$ is the optimal value of $\mu$ obtaining from the $i$ th Lagrangean. There is clearly no Nash equilibrium. There would be one iff:

but, in general, we expect that:

$$
\mu_{1}=\mu_{2}<=>c_{1} c_{2}=\left(b_{1}-\lambda_{1}\right)\left(b_{2}-\lambda_{2}\right)
$$

$$
\mu_{1}>\mu_{2}<=>c_{1} c_{2}>\left(b_{1}-\lambda_{1}\right)\left(b_{2}-\lambda_{2}\right)
$$

as outlined in the introductory section. This is the condition that preferences should satisfy at the optimum. It has to be complemented by one describing the economic environment that would make them sensible in practice.

This second condition emerges by asking, how the above differentiation in the $\mu$ 's reflect on (5)? One way to approach the difference is to resort to the equation of exchange: $M V=P Q$, where $V$ is the velocity of the circulation of money and $Q$ is real output. From this equation:

$$
\Delta M=\Delta Q+\Delta P-\Delta V
$$

The balanced budget proponent would be one favoring price stability and in general, $\Delta P=\Delta V$ when $\Delta V \neq 0$ in the short-run:

$$
\mu_{2}=1+\frac{\Delta B}{P T+\Delta Q}
$$

But, the legislator advancing pork-barrel spending bills would not simply "bother" with such "details":

$$
M_{l}=1+\frac{\Delta B}{P T+\Delta Q+\Delta P-\Delta V}
$$

It follows that:

$$
\mu_{1}>\mu_{2}<=>\Delta V>\Delta P
$$

This is the condition under which the reservations of the thrifty legislator would be sensible in practice, ceteris paribus, that is, given the preferences expressed in the relevant debate. It is a condition about price stability: price reductions/increases should be less than circulation velocity reductions/increases. It is the condition about the economic environment in which the legislators debate and has to be combined with the earlier condition, $\left(8^{\prime}\right)$, over preferences.

The outcome of this combination may be found by equating (5") with (6), and (5') with (7), and obtaining:

$$
\Delta Q_{1}=\frac{b_{1}-\lambda_{1}}{c_{1}-b_{1}+\lambda_{l}} \Delta B-P T-\Delta P+\Delta V
$$

and

$$
\Delta Q_{2}=\frac{c_{2}}{b_{2}-c_{2}-\lambda_{2}} \Delta B-P T
$$


With

$$
\Delta Q_{1} \gtrless \Delta Q_{2}<=\Delta P-\Delta V \gtrless \frac{c_{1} c_{2}-\left(b_{1}-\lambda_{1}\right)\left(b_{2}-\lambda_{2}\right)}{\left(c_{1}-b_{1}+\lambda_{1}\right)\left(b_{2}-c_{2}-\lambda_{2}\right)} \Delta B
$$

Combining (8") with (12) implies that $\Delta Q_{1}<\Delta Q_{2}$ iff, of course, the denominator of (12) is as positive as the numerator. But, if this is not the case, if $\left(c_{1}-b_{1}+\lambda_{1}\right)\left(b_{2}-c_{2}-\lambda_{2}\right)<0$ and if $\Delta P-\Delta V<0$ we will continue having $\Delta Q_{1}<\Delta Q_{2}$, when the absolute value of the left-hand side of (12) exceeds that of the right-hand side. If not, it will imply that the pork-barrel spending under debate is actually growth-enhancing for the overall economy and should not be blocked by the thrifty delegate. Much more so when such spending induces government borrowing, and growth can help check the debt-to-output ratio. The same again holds if $\Delta P-\Delta V>$ 0 but $\left(c_{1}-b_{1}+\lambda_{1}\right)\left(b_{2}-c_{2}-\lambda_{2}\right)<0$, and if both of these expressions were positive with the former exceeding absolutely the latter. It all depends on the interplay between these two expressions. The use of more complicated utility functions like the Cobb-Douglas or Stone-Geary ones would only complicate the expression describing the preferences, while the introduction of interest payments on debt would only turn in this expression $\Delta B$ to $\Delta B-r B$. And, the use of more complicated expressions about $\Delta M$, deriving perhaps from outside the context of the equation of exchange, would only modify the condition (8") regarding the economic conjuncture under which decisions are made. More interesting would be rather to see how the introduction of logrolling qualifies our basic conclusion.

The trading among legislators of their votes on the different bills before an assembly is usually approached through its voting dimension (see e.g. Wilson, 1969; Tullock, 1970). Here, logrolling takes the form that once player 2 realizes that some pork-barrel spending cannot be avoided, player 1 might be convinced by 2 to claim such spending within the context of a balanced budget, i.e. to maximize (1) constrained by (4) rather than (3), so that the maximum under the circumstances growth, i.e. $\Delta Q_{2}>\Delta Q_{1}^{\prime}$, may be ensured, where the prime (') connotes to this maximization problem. Alternatively, 1 might persuade 2 to maximize (2) subject to (3), to accommodate that is pork-barrel spending, promising a $\Delta Q_{2}^{\prime}>\Delta Q_{1}$, that is that 1 will not hurt 2's growth aspirations, where the prime refers to this now maximization problem. Such promises are possible because both agents acknowledge real output growth to be the principal component of any policymaking independently of the prevailing economic momentum, that is of the relationship between $\Delta P$ and $\Delta V$. As it may be seen from (5') and (5"), the adoption of common budget constraints, eliminates from the calculations the relationship between prices and circulation velocity. The economic momentum does not matter anymore and only the conditions over preferences corresponding to the "primed" optimization problems remain significant in shaping konjunkturpolitik:

$$
\mu_{1}^{\prime}>\mu_{2}<=>c_{2}\left(c_{1}+\lambda_{1}^{\prime}\right)>b_{1}\left(b_{2}-\lambda_{2}\right)<=>\Delta Q_{2}>\Delta Q_{1}^{\prime}
$$

and

$$
\mu_{1}>\mu_{2}^{\prime}<=>c_{1}\left(c_{2}+\lambda_{2}^{\prime}\right)>b_{2}\left(b_{1}-\lambda_{1}\right)<=>\Delta Q_{2}^{\prime}>\Delta Q_{1}
$$

respectively. Trustworthy legislators can cooperate to the mutual and societal benefit to the extent that pork-barrel-spending induced debt accumulation cannot be avoided.

\section{Concluding Remarks}

Two are the points made by this note, namely (i) that legislator preferences may adjust under any economic conjuncture to turn any pork-barrel spending to a growth- enhancing venture, and (ii) that logrolling may make this a lot easier. Pork-barrel projects are certainly redistributive ones and it is in the hands of politicians to be deliberating them under a stringent growth clause. A century ago, the Louisiana Senator Joseph E. Ransdell (1916) was writing: 'In its general acceptation, 'pork,' as applied to Congressional legislation, means an appropriation by Congress for an unworthy purpose that is not for the public good and useful to the nation, but is for the private benefit of the Congressman who secures it, or for one or more of his constituents. The term conveys the idea that certain classes of legislation such as pensions, public buildings, rivers, and harbors, and some other bills, if not wholly reprehensible, contain many improper items for objects which should have no place in acts of Congress. These bills are made to appear similar to the parable of the sower who got the cockle mixed with his wheat. Their wise provisions which help the public and promote the general welfare constitute the wheat, and the selfish, unjust, and unwise items are the cockle, or 'pork'", (p. 43). And, the senator then asks for the removal of the cockle. This is what we do point out herein, too. Moreover, echoing "Director's law" regarding redistributive politics, pork-barrel spending appears to favor the middle class, which is certainly growth-enhancing per se (Dixit \& Londregan, 1998), contingent, of course, upon the removal of the "cockle". 


\section{Acknowledgements}

I am grateful to an anonymous reviewer for useful comments and suggestions. Any errors or omissions are my own.

\section{References}

Battaglini, M., \& Coate, S. (2008). A Dynamic Theory of Public Spending, Taxation and Debt. American Economic Review, 98(1), 201-236. http://dx.doi.org/10.1257/aer.98.1.201

Chari, V., \& Cole, H. L. (1995). A Contribution to the Theory of Pork Barrel Spending. Staff Report from Federal Reserve Bank of Minneapolis No. 156. Retrieved from http://www.minneapolisfed.org/research/sr/sr156.pdf

Dixit, A., \& Londregan, J. (1998). Ideology, Tactics, and Efficiency in Redistributive Politics. Quarterly Journal of Economics, 113(2), 497-529. http://dx.doi.org/10.1162/003355398555667

Lanciay, F., \& Russoz, A. (2013). A Dynamic Politico-Economic Model of Intergenerational Contracts. University of Vienna Working Paper No. 1304. Retrieved from http://mailbox.univie.ac.at/papers.econ

Lizzeri, A. (1999). Budget Deficits and Redistributive Politics. Review of Economic Studies, 66(4), 909-928. http://dx.doi.org/10.1111/1467-937X.00113

Ransdell, J. E. (1916). The High Cost of the Pork Barrel. Annals of the American Academy of Political and Social Science, 64. Public Administration and Partisan Politics, 43-55.

Ricciuti, R. (2004). Legislatures and Government Spending: Evidence from Democratic Countries. International Centre for Economic Research Working Paper No. 20/2004. Retrieved from http://www.icer.it/docs/wp2004/Ricciuti20-04.pdf

Tullock, G. (1970). A Simple Algebraic Logrolling Model. American Economic Review, 60(3), 419-426.

Wilson, R. (1969). An Axiomatic Model of Logrolling. American Economic Review, 59(3), 331-341.

\section{Copyrights}

Copyright for this article is retained by the author(s), with first publication rights granted to the journal.

This is an open-access article distributed under the terms and conditions of the Creative Commons Attribution license (http://creativecommons.org/licenses/by/3.0/). 